\title{
A CONTRIBUIÇÃO TEÓRICA DE MICHAEL MANN EM UM ESTUDO COMPARATIVO SOBRE A COOPERAÇÃO INTERMUNICIPAL: FRANÇA E BRASIL ${ }^{1}$
}

\author{
Juliana Nunes ${ }^{2}$
}

\section{Resumo}

Este texto aborda as práticas de cooperação entre comunas que se desenvolvem na França e no Brasil. Por um lado, trata-se de demonstrar a importância do método comparativo para ampliar a reflexão sobre os processos de formação e de difusão de estruturas de cooperação intermunicipal em dois modelos de Estado: o modelo federal brasileiro e o modelo unitário e descentralizado francês. Por outro lado, ressaltamos a importância de algumas ferramentas teóricas desenvolvidas pelo sociólogo Michael Mann para enriquecer os estudos comparativos em Geografia Política. Enfim, discutimos um conjunto de problemáticas que se apresentam nos dois países e que ampliam a reflexão sobre as alternativas e entraves da cooperação intermunicipal em dois modelos de Estado distintos.

Palavras-chave: cooperação, comparação, território, municípios, descentralização.

\section{THE THEORETICAL CONTRIBUTION OF MICHAEL MANN IN A COMPARATIVE STUDY ON}

\footnotetext{
1 Artigo originalmente publicado em francês na Revista L'Espace Politique. NUNES Juliana. «La coopération intercommunale en France et au Brésil, analyse suivant l'approche de Michael Mann ». L'Espace Politique [on line], 14 | 2011-2.

${ }^{2}$ Doutora em Geografia - Université Jean Moulin Lyon 3 (CAPES - Bolsa de Doutorado Pleno no Exterior.

Bolsista de Pós-Doutorado Júnior do CNPq. Universidade Federal do Rio de Janeiro. Email: jnunesrodrigues@yahoo.com.br
} 
NUNES, J. A contribuição teórica de Michel Mann em um estudo...

\title{
INTER-MUNICIPAL COOPERATION: FRANCE AND BRAZIL
}

\begin{abstract}
This paper focuses on practices of inter-municipal cooperation taking place in France and in Brazil. The intention is to reflect about the increase of the local scale's strength in societies with distinct conceptions about the role of the State and about its mechanisms of social control. On the one hand, the aim is to underscore the processes of formation and diffusion of intermunicipal cooperative structures occurring in Brazil and in France by considering their dissimilar institutional arrangements. On the other hand, we want to raise the theoretical framework developed by Michael Mann, who brings innovative features to enhance analysis in the field of Political Geography. Finally, we derive a set of issues that arise in the two countries and broaden the debate on the opportunities and barriers to inter-municipal cooperation in two very different models of state.
\end{abstract}

Key-words: cooperation, comparison, municipality, territory, decentralization.

\section{Introdução}

Este texto retoma a importância do método comparativo em Geografia para promover uma discussão sobre as práticas cooperativas intermunicipais que se desenvolvem na França e no Brasil. Ainda que esses dois países sejam muito distintos do ponto de vista sócio-econômico e geográfico, constituem dois modelos de Estado - a França, um Estado unitário e descentralizado; o Brasil, um Estado federal - que seguiram uma tendência de descentralização de suas estruturas político-institucionais. Além disso, os dois países conheceram um fenômeno de multiplicação de práticas cooperativas intermunicipais. Nesse contexto, parte-se da hipótese que a forma de organização espacial da política afeta a 
NUNES, J. A contribuição teórica de Michel Mann em um estudo...

maneira como a cooperação intermunicipal é concebida e se desenvolve em cada um desses modelos.

O tema recupera um problema clássico da Geografia, o da distribuição de equipamentos e serviços públicos nos territórios nacionais. Situamo-nos assim no centro de um debate que interroga sobre a gestão das distâncias e proximidades espaciais na oferta de bens e serviços públicos. A pesquisa desenvolvida se apóia ainda sobre uma premissa geral: as decisões e ações que emanam do aparelho do Estado afetam de maneira inevitável a sociedade e o território. Esses últimos, por sua vez, influenciam a forma e a dinâmica de funcionamento de facto dos Estados, revelando as imbricações complexas que se estabelecem entre sociedade, Estado e território. Tal perspectiva retoma o interesse da Geografia pela dimensão concreta que resulta da organização da política do Estado no espaço e de sua capacidade de garantir o interesse público em todo o território nacional (MANN, 1997; CASTRO, 2009).

Por cooperação territorial entendemos os acordos voluntários entre duas ou mais estruturas de gestão local (comunas, no caso da França; municípios, no caso brasileiro), voltados à maximização de recursos materiais, humanos e técnicos, capazes de beneficiar ao conjunto de estruturas locais participantes. Tais acordos definem regras de funcionamento e de inserção de cada município ou comuna em uma estrutura de cooperação intermunicipal, que se concretiza pela definição de novos limites territoriais para enfrentamento de problemas e elaboração de ações conjuntas. Neste sentido, as práticas cooperativas intermunicipais tornam-se um objeto de estudos eminentemente geográfico: o território "da cooperação" assim fixado é não somente afetado por políticas públicas, mas o próprio referencial das relações intermunicipais. Em outras palavras, os limites territoriais da cooperação são reconhecidos e compartilhados pelo conjunto de parceiros, o que lhes possibilita identificar problemas comuns e meios de intervenção. Em última análise, "é o território que ordena a cooperação" (JOUVE, 2007, p. 46). 
NUNES, J. A contribuição teórica de Michel Mann em um estudo...

O qualificativo "territorial" é assim empregado para valorizar municípios e comunas enquanto espaços políticos, dotados de contiguidade e limites precisos, nos quais os efeitos das ações e decisões do poder público são identificáveis e mensuráveis (CASTRO, 2005). Retomamos assim a ideia de que o espaço político é afetado pelas ações das instituições políticas, cujos efeitos são reconhecidos no interior de limites territoriais definidos. As instituições políticas, por sua vez, afetam as diferentes dimensões da vida social, inclusive a organização do território. O espaço político é assim o espaço da norma, o espaço de exercício de direitos e deveres em prol do convívio social.

O presente texto deriva de nossa tese de doutorado realizada na França em 2010. Na ocasião, foi realizado um amplo estudo sobre as práticas cooperativas intermunicipais a partir de mapeamentos realizados nas escalas nacionais da França e do Brasil, além de entrevistas de campo junto a gestores e funcionários públicos locais. Nos limites deste artigo, propomos apresentar alguns argumentos que retomam a importância do método comparativo em Geografia para refletir sobre os efeitos territoriais da política em realidades sócio-econômicas e espaciais distintas. Com o intuito de melhor situar o leitor, algumas características dos Estados francês e brasileiro serão retomadas. Apresentaremos em seguida algumas ferramentas teóricas desenvolvidas por Michael Mann e a relevância de sua contribuição para enriquecer os estudos comparativos em Geografia Política. Enfim, um conjunto de temáticas que resultam de nossas entrevistas de campo revela maneiras diferentes de conceber e de desenvolver a cooperação intermunicipal em cada um dos modelos de Estado estudados. Esperamos assim ampliar a compreensão sobre as mediações capazes de afetar as práticas cooperativas intermunicipais em dois modelos de Estado diferentes. 
NUNES, J. A contribuição teórica de Michel Mann em um estudo...

\section{Comparar, por que e como fazer?}

Comparar requer um esforço de relativização, de questionamento de concepções e de sistemas de pensamento comumente aceitos. Por esta razão, alguns autores afirmam que a comparação é antes uma estratégia de pesquisa do que um método de investigação propriamente dito (DUPRÉ et. Al., 2003, p.9). Comparar é "fazer da alteridade uma forma de conhecimento", ou ainda, valorizar o "desvio" como estratégia de apreensão da realidade. Tantas são as formulações que nos lembram de que a comparação nos transporta para o registro de uma epistemologia fundamentalmente dialética, na qual "a negação de Si através da confrontação com o Outro constitui uma ferramenta privilegiada de conhecimento do Mesmo" (DUPRÉ et. Al., 2003, p. 9) ${ }^{3}$.

O "desvio comparativo" nos conduz, entretanto, a uma pergunta inquietante: como comparar sociedades e Estados tão distintos? Ora, ao propomos um olhar comparativo entre a França e o Brasil não buscamos proximidades ou coisa que o valha. Antes, $o$ interesse é o de salientar traços que nos possibilitam interpretar manifestações de um dado fenômeno em realidades distintas. Dito de outro modo, é porque França e Brasil constituem modelos diferentes de organização espacial da política - a França, um modelo unitário; o Brasil, um modelo federal - que a comparação nos pareceu enriquecedora. Observar "como fazem os outros" contribui assim para a compreensão de nossos próprios limites e possibilidades. Em síntese, a comparação se reclama de uma virtude heurística, que através da dúvida e do questionamento enriquece o conhecimento de nossa própria realidade. A comparação produz assim um distanciamento necessário para nos descentrar dos dados considerados como as únicas alternativas possíveis. Em última instância, a comparação serve para revelar o

\footnotetext{
${ }^{3}$ Tradução da autora. Versão original : « Voilà autant de formulations qui rappellent que la comparaison nous place « d'emblée sur le registre d'une épistémologie fondamentalement dialectique en vertu de laquelle la négation de Soi par confrontation à l'Autre reste un moyen privilégié de la connaissance du Même» (DUPRÉ et. Al., 2003, p. 9).
} 
NUNES, J. A contribuição teórica de Michel Mann em um estudo...

que a cooperação intermunicipal quer dizer "aqui" e "lá", porque as práticas cooperativas se referem, antes de tudo, ao significado que os atores locais lhe atribuem (BADIE e HERMET, 2001, p.2). França e Brasil são assim quadros de referência para o estudo das práticas cooperativas locais.

O "problema da comparabilidade" torna não menos importante o recurso aos conceitos, os "denominadores comuns" dos objetos submetidos à comparação (GAZIBO e JENSON, 2004, p. 53-54). Porque é necessário «ler» as diferenças entre os Estados francês e brasileiro, consideramos oportuno salientar as ferramentas teóricas desenvolvidas por Michael Mann. Tais ferramentas de análise tratam da capacidade do Estado de afetar as rotinas sociais e estabelecer regras claras e respeitadas em todo o território nacional. O diálogo entre a Geografia e disciplinas vizinhas nos parece assim não somente salutar, mas uma postura intelectual inevitável.

\section{O poder infra-estrutural dos Estados e a Geografia}

Longe de resgatar o percurso de uma Geografia Política clássica, propomos mobilizar algumas noções que consideramos enriquecedoras para o exercício da comparação em Geografia Política. Neste exercício, é importante considerar os próprios atributos do Estado enquanto problema geográfico, e não como um mero dado da realidade (RETAILLÉ, 1997, p. 146). Fundamentalmente, "o Estado é um problema para a Geografia em razão de sua natureza territorial"; "é o território que confere substância ao Estado" (CASTRO, 2009, p.2). Posto isso, trata-se de refletir sobre o território enquanto base material para o exercício do poder do Estado na organização do cotidiano das diferentes sociedades. Nessa perspectiva, as ferramentas teóricas desenvolvidas pelo sociólogo Michael Mann oferecem pistas analíticas para os estudos comparativos em Geografia Política.

O propósito de Michael Mann repousa sobre uma ideiachave: a da necessidade do território para o exercício do poder dos Estados (MANN, 1984, 1992). Para Mann, é a base territorial que 
NUNES, J. A contribuição teórica de Michel Mann em um estudo...

possibilita ao Estado penetrar a sociedade civil, no exercício de suas prerrogativas que afetam as rotinas sociais. Neste sentido, o Estado exerce um poder autônomo que o diferencia da sociedade civil; só o Estado é capaz de estabelecer e fazer cumprir normas que ordenam as rotinas por todo o território nacional. Ao fim e ao cabo, é graças a sua autonomia que o Estado é capaz de cumprir funções que nenhum grupo social é capaz de cumprir.

Longe de esgotar a contribuição de Michael Mann para as ciências sociais, em geral, e para a Geografia, em particular, podemos ressaltar algumas de suas premissas que serão úteis para compreender diferenças fundamentais entre o Estado francês e o brasileiro. Não é portanto demais lembrar que o projeto teórico de Michael Mann ultrapassa amplamente as ambições desta breve apresentação ${ }^{4}$.

Ao problematizar o Estado como um objeto teórico, Michael Mann se afasta da concepção do Estado como simples produto das estruturas pré-existentes na sociedade civil. Com efeito, ainda que de maneira simplista e esquemática, tanto a tradição marxista, quanto as tradições liberal e funcionalista, valorizam o Estado enquanto "arena", enquanto "lugar", onde os conflitos de classe, entre grupos ou ainda entre indivíduos se manifestam e se institucionalizam. Em outras palavras, tais vertentes não consideram o Estado como um problema em si mesmo, mas como produto de conflitos que se originam e se reproduzem na sociedade. Apesar dos avanços teóricos realizados por essas correntes intelectuais, Mann as considera insuficientes,

${ }^{4}$ Referimo-nos aqui ao projeto de Michal Mann intitulado TheSources of Social Power, que engloba dois volumes: A History from the Beggining to $1760 \mathrm{AD}(1986)$ e The Rise of Classes and Nation-States, 17601914. O terceiro volume, dedicado à época contemporânea, ainda não foi publicado. Para uma introdução sobre o projeto de Michael Mann, ver Schroeder, Ralph. "Introduction: the IEMP model and its critics". In Hall, J. and Schoroeder, R. (ed.). An anatomy of power: the social theory of Michael Mann. Cambridge: Cambridge University Press, 2006. pp. 1-16. 
NUNES, J. A contribuição teórica de Michel Mann em um estudo...

porque negam a autonomia do Estado para regular, de forma original e independente, as rotinas. $\mathrm{O}$ autor propõe assim uma teoria dual, capaz de reunir as diferentes dimensões do Estado para esclarecer seus mecanismos de exercício de poder.

\section{O Estado segundo Michael Mann}

De acordo com Michael Mann (1984), é possível caracterizar o Estado segundo duas perspectivas principais: a perspectiva institucionalista e a perspectiva funcionalista. Assim, "o Estado pode ser definido em relação ao que parece, institucionalmente, ou em relação ao que realiza, quer dizer, em relação a suas funções" (MANN, 1997, p. 60). O autor recupera assim alguns atributos do Estado já bastante explorados na literatura sobre o tema: um conjunto de instituições e um corpo de funcionários que se distinguem; uma centralidade, pois seu poder emana de um centro decisório; o monopólio da autoridade para elaborar e sancionar leis; o monopólio dos meios de coerção para o exercício da violência legítima ${ }^{5}$. Todos esses atributos tornam o Estado facilmente reconhecível pelos membros da sociedade civil. Por um lado, seu caráter institucional é identificado através de seu corpo de funcionários e suas instituições; por outro lado, seu caráter funcional deriva das normas elaboradas e estabelecidas para ordenar as rotinas sociais, além da realização de políticas e ações públicas que atendem às necessidades dos seus cidadãos. A partir dessa definição mínima, o autor levanta questões sobre o poder das elites dirigentes e do próprio Estado em relação aos movimentos da sociedade civil. Como, afinal, distinguir o poder de influência das elites de outras formas de poder que se manifestam na sociedade? Para responder, Mann sofistica seus argumentos, distinguindo o poder despótico das elites do poder infra-estrutural do Estado. $\mathrm{O}$

${ }^{5} \mathrm{O}$ autror retoma assim os atributos clássicos do Estado, notadamente as reflexões de Marx, Weber, Durkheim...para desenvolver sua discussão original sobre o poder infra-estrutural dos Estados. Sobre as noções apropriadas e discutidas por Michael Mann, ver o artigo de Schroeder, R.,2006. 
NUNES, J. A contribuição teórica de Michel Mann em um estudo...

autor esclarece que o poder despótico se refere justamente ao poder das elites do Estado - as elites dirigentes - no exercício de ações que ultrapassam a simples organização das rotinas sociais. $O$ poder despótico é, desse modo, um poder autoritário, que não passa pelas negociações usuais entre o Estado e a sociedade. Em poucas palavras, o poder despótico é o poder autônomo das elites.

$\mathrm{O}$ segundo tipo de poder, amplamente difundido nas sociedades capitalistas e democráticas, é o poder infra-estrutural dos Estados. Trata-se do poder de que o Estado desfruta para alcançar a sociedade civil e fazer valer suas decisões de maneira logística e racional, em todo o território nacional.

Mann explica ainda que o poder infra-estrutural se expandiu nas sociedades industriais, graças ao avanço dos meios técnicos necessários à penetração do Estado no território. $\mathrm{O}$ poder infra-estrutural resulta assim de todos os meios pelos quais o Estado regula o cotidiano, sem que para tanto precise solicitar sistematicamente a autorização da sociedade civil. Isso porque o poder infra-estrutural é um poder negociado, que resulta das regras de funcionamento do próprio regime democrático. O Estado pode, por exemplo, cobrar impostos e taxas, porque a população aceita esse ônus; o pagamento de impostos é um elemento constitutivo do Estado democrático e faz parte das negociações usuais necessárias à organização do cotidiano social (WEISS, 2006, p.172-173). Desta maneira, Michael Mann considera que quanto maior o poder infra-estrutural do Estado, maior sua capacidade de controlar as rotinas e ordenar o cotidiano em seu território (MANN, 1997, p.61). O poder infra-estrutural do Estado é assim imenso, e efetivamente submetido ao crivo da sociedade na ocasião dos escrutínios eleitorais. É o que distingue, aliás, as sociedades capitalistas e democráticas das sociedades históricas, mais vulneráveis ao poder das elites governantes.

As categorias analíticas desenvolvidas por Mann são certamente modelos abstratos; na realidade, os dois tipos de poder identificados pelo autor se conjugam de diversas maneiras (MANN, 1997, p. 63). Todavia, essas ferramentas teóricas são 
NUNES, J. A contribuição teórica de Michel Mann em um estudo...

interessantes, na medida em que nos conduzem a uma reflexão sobre as diferentes capacidades dos Estados para afetar as rotinas sociais.

Se a Geografia Política classicamente se interessou pelos conflitos territoriais e pelas relações de força entre Estados, o poder infra-estrutural dos Estados identificado por Michael Mann nos situa em outra dimensão do político, aquela de produção da legitimidade social (LEVY, 1994). Em se tratando de práticas cooperativas intermunicipais, passam a nos interessar as negociações, as relações que derivam do aparelho dos Estados e que se reproduzem nos limites dos territórios nacionais. Nesse sentido, compartilhamos com Castro (2009, p. 9) a ideia de que « da mesma maneira que é possível falar de um modelo de Estado territorial moderno como ponto de partida analítico, é possível falar de uma administração pública racional como modelo analítico". A organização política dos Estados no espaço constitui assim um ponto de partida para pensarmos as diferenças em relação aos seus poderes infra-estruturais e os seus efeitos mais concretos.

\section{França e Brasil, dois modelos de Estados}

A centralização e a forte burocratização constituíram a marca do Estado francês e de sua capacidade para estabelecer e difundir os valores republicanos por todo o território nacional. A fina malha administrativa comunal, associada à existência de um denso corpo de funcionários, contribuíram para a difusão de códigos de conduta e valores comuns, para o ordenamento das práticas sociais e também para a consolidação de um sistema eficaz de provimento de bens e serviços públicos no território. Nos termos de Michael Mann, pode-se dizer que na França o Estado foi bem sucedido no exercício de seu poder infra-estrutural, através da difusão de valores e do ordenamento das rotinas sociais. Neste quadro, as comunas francesas ganham um significado muito peculiar, tanto porque constituem o espaço de organização política da vida cotidiana quanto pelos valores simbólicos de seus limites 
NUNES, J. A contribuição teórica de Michel Mann em um estudo...

territoriais ${ }^{6}$. O grande número de comunas - mais de $36000 \mathrm{em}$ um território nacional que é 15 vezes menor que o brasileiro - foi assim favorável à fixação das bases do modelo de Estado francês unitário e centralizado (RICHARD e COTTEN, 1983, p. 28).

Por outro lado, a organização territorial do Estado brasileiro está fundamentada no federalismo, que pressupõe uma repartição equilibrada de competências e recursos entre as escalas de poder. Historicamente, a União é a escala de controle de recursos, responsável pelo ordenamento territorial e pelo exercício de funções redistributivas capazes de equilibrar o pacto. No entanto, em diversos momentos da história política brasileira, o regime federal foi desrespeitado, e o Governo Federal interveio nos espaços de ação municipais e estaduais, rompendo o equilíbrio do pacto. Em 1988, com o retorno da democracia, o pacto federativo estabelecido pela Constituição reza pela cooperação entre as escalas de poder e consagra o Município como ente federativo. Uma das particularidades do modelo federativo brasileiro é assim a tripla soberania: tanto a União, quanto os Estados federados e os Municípios são entes federativos, autônomos no exercício de suas competências definidas pela Constituição. Em outras palavras, não há possibilidade de hierarquia ou imposição de normas de uma escala de decisão às outras; cada escala de decisão é soberana no

${ }^{6}$ Cabe lembrar que, na França, as comunas têm um valor simbólico bastante peculiar, que remonta aos debates ocorridos à luz da Revolução. Tais debates se referiam, entre outros temas, à reforma da divisão político-territorial francesa, tendo-se em vista assegurar a todos os cidadãos iguais condições de acesso aos serviços do Estado. Foi definido que os limites comunais preservariam os limites das antigas paróquias existentes durante o Antigo Regime, respeitando-se os valores sociológicos da comuna enquanto espaço de organização da vida comunitária rural. Por outro lado, sobretudo nas cidades então incipientes, a comuna passou a ser o espaço de organização da vida política dos cidadãos iguais em direitos em deveres. Até os dias de hoje, as comunas preservam seus significados enquanto espaços de organização do cotidiano, de pertencimento, e também de primeira escala de organização da vida política. 
NUNES, J. A contribuição teórica de Michel Mann em um estudo...

exercício de suas funções dentro de seus limites territoriais. A Constituição de 1988 inaugura também um tipo de federalismo cooperativo, que pressupõe competências difusas e compartilhadas entre as três escalas decisórias. Tal característica traz novos desafios para a coordenação de ações e definição de políticas públicas conjuntas entre os entes federados. A complexidade do federalismo brasileiro resulta assim dos laços que se estabelecem entre Governo Federal, Estados e Municípios para o equilíbrio do pacto.

Não é demais lembrar que, com um território de dimensões continentais, o Brasil conta com pouco mais de 5.500 municípios ${ }^{7}$, desigualmente distribuídos no território nacional. Este dado é significativo para refletirmos sobre a capacidade infra-estrutural do Estado brasileiro, que depende não apenas das redes de transporte e de comunicação, mas também dos municípios que asseguram o provimento de bens e serviços públicos no interior do país. Posto isso, podemos discutir algumas conclusões da pesquisa realizada.

\section{A cooperação intermunicipal na França e no Brasil, traços gerais}

$\mathrm{Na}$ França, apesar das políticas de regionalização lançadas pelo Estado nos anos 1950, é a partir de 1982 que as propostas de descentralização são efetivamente postas em prática. Com efeito, a lei de março de 1982 define uma nova divisão de competências entre as escalas territoriais - Estado, Regiões, departamentos e comunas. No entanto, tais divisões permanecem como escalas de gestão administrativas, no respeito das leis estabelecidas pelo Estado unitário. Trata-se, antes, de reformar a estrutura do Estado tendo-se em vista uma melhor adaptação da França à intensificação dos problemas urbanos, aos conflitos territoriais e, sobretudo, ao contexto europeu. Dessa maneira, mudanças de ordem jurídica e

${ }^{7}$ Segundo os resultados parciais do censo demográfico 2010, do IBGE, o Brasil conta com um total de 5565 municípios. 
NUNES, J. A contribuição teórica de Michel Mann em um estudo...

política foram inauguradas e estimularam a propagação das estruturas de cooperação inter-comunais (EPCIs).

As principais mudanças se referem à definição de novas leis, ao longo dos anos 1990, que estimularam e compensaram práticas cooperativas para a elaboração de projetos de desenvolvimento territorial. Por outro lado, no contexto europeu, as comunas francesas são consideradas de escala insuficiente para competir com as grandes regiões econômicas da União Européia. A União Européia (UE) constitui, assim, um ator político e econômico importante, que financia projetos de desenvolvimento econômico firmados entre comunas, ou ainda contratos estabelecidos entre as estruturas de cooperação inter-comunais francesas e regiões de outros países da UE.

Em suma, mudanças de ordem política e econômica foram favoráveis ao sucesso das EPCIs na França. A fase atual se caracteriza por um real engajamento das comunas em projetos que compreendem melhorias dos transportes públicos, das escolas municipais, da limpeza pública e coleta de lixo, além dos projetos de criação de parques industriais e de vantagens ao comércio local para estimular o desenvolvimento econômico. Tais estruturas se apóiam ainda sobre a possibilidade de arrecadar recursos próprios, o que reduz a concorrência entre as comunas participantes e favorece a cooperação e o planejamento territorial.

No Brasil, ainda que inaugurados pela Constituição de 1937, os Consórcios Intermunicipais ganharam destaque na agenda nacional em 2005 (CALDAS, 2008), quando foi promulgada a lei 11. 107 que regula a formação de Consórcios Públicos Intermunicipais ${ }^{8}$. Essa legislação foi lançada e aprovada com o intuito de reduzir as incertezas acerca das práticas cooperativas intermunicipais, que se há muito conhecidas, tiveram até então pouca expressão no cenário nacional. Com a definição de normas claras e minuciosas, os Consórcios Intermunicipais tornaram-se um

${ }^{8}$ Lei 11.107 sobre os Consórcios Públicos Intermunicipais e o decreto $\mathrm{n}^{\circ}$ 6.017 de 2007. 
NUNES, J. A contribuição teórica de Michel Mann em um estudo...

instrumento de ação conjunta nos diversos domínios das políticas sociais, notadamente aquelas que exigem a mobilização de recursos importantes, como é o caso das políticas de saúde. Tais iniciativas se inscrevem no processo de consolidação do modelo brasileiro de federalismo cooperativo, mais aberto à participação da sociedade civil e às experiências inovadoras no campo das políticas públicas municipais.

Diferentemente das EPCIs francesas, a maior parte dos Consórcios Intermunicipais brasileiros não se encarregam da elaboração de projetos de desenvolvimento territorial. Na França, as EPCIs atuam de maneira global, de forma a coordenar as políticas públicas para o desenvolvimento de projetos a longo prazo para o "território da cooperação". No Brasil, os Consórcios se ocupam de políticas públicas setoriais e de maneira fragmentada, o que dificulta o desenvolvimento de planos de ação integrados. Esse gargalo vem sendo superado por alguns consórcios de desenvolvimento, como é o caso do Consórcio de Desenvolvimento do Leste Fluminense e outros que se desenvolveram no Rio Grande do Sul, mas tais experiências são ainda pouco numerosas. A maior parte dos Consórcios atua assim de forma a promover melhorias na oferta de equipamentos, de infra-estruturas e para a captação de recursos que os municípios sozinhos seriam incapazes de mobilizar. Assim, a cooperação intermunicipal se desenvolve nos campos da administração, do suporte técnico, da capacitação de pessoal e da prestação de serviços nos campos da saúde, da educação, do saneamento básico, da assistência social, da proteção do meio ambiente e da gestão de recursos naturais, entre outros exemplos ${ }^{9}$. Apesar das diferenças,

${ }^{9}$ Em 2005, o Brasil contava 4537 municípios membros de Consórcios Intermunicipais; isto é, $81 \%$ dos municípios. Neste conjunto, os municípios menos povoados (com menos de 10000 habitantes) se destacam pela ampla participação nesse percentual, especialmente no campo da saúde (40\%). Com efeito, o setor da saúde compreende o maior percentual de municípios consorciados (42\%), graças às próprias regras do Sistema Nacional de Saúde que estimulam a cooperação inter- 
NUNES, J. A contribuição teórica de Michel Mann em um estudo...

tanto os Consórcios brasileiros quanto as EPCIs francesas seguem a mesma via das práticas cooperativas intermunicipais para reforçar o papel das estruturas de gestão local na oferta de serviços e equipamentos públicos. Na França e no Brasil, a cooperação intermunicipal se consolida como uma estratégia para $o$ cumprimento de competências locais, através do compartilhamento de recursos e a maximização de economias de escala. Além disso, esse fenômeno emerge e se amplia em contextos de valorização das lógicas locais no processo de definição e tratamento de problemas públicos. Posto isso, podemos ressaltar algumas características identificadas durante a realização de nossas entrevistas de campo ${ }^{10}$.

\section{A cooperação intermunicipal na França e no Brasil, um olhar comparativo}

Nos argumentos que justificam a criação de estruturas de cooperação intermunicipal encontra-se o problema de gestão das distâncias. Na França, as comunas são consideradas de tamanho insuficiente para equacionarem problemas relacionados ao crescimento das cidades e à inserção da França no mercado europeu. No Brasil, as distâncias entre as sedes municipais são significativas, e a criação de Consórcios tem relação com a necessidade de ampliar a oferta de bens e serviços públicos locais. No entanto, os modelos de Estado francês e brasileiro se revelaram

municipal para a gestão de equipamentos e a prestação de serviços mais onerosos. Em seguida, aparecem os Consórcios de meio ambiente (9\%), do saneamento (8\%), do turismo (8\%) e dos transportes (7\%). Dados tratados pelo autor a partir dos resultado das pesquisas "Perfil dos Municípios Brasileiros - Gestão Pública 2005 », do IBGE - Instituto Brasileiro de Geografia e Estatística - www.ibge.gov.br.

${ }^{10}$ Entrevistas realizadas na Região Rhône-Alpes, na França, e no Estado do Rio de Janeiro, Brasil, junto a funcionários e responsáveis pelas EPCIs e Consórcios Intermunicipais, durante o ano de 2008. Para maiores detalhes sobre a metodologia das enquetes e as estruturas intermunicipais visitas, ver AUTOR, 2010. 
NUNES, J. A contribuição teórica de Michel Mann em um estudo...

significativos para compreender as sutilezas da cooperação intermunicipal nos dois países.

A cooperação inter-comunal dita de projeto foi inaugurada na França nos anos 1990, mas as estruturas inter-comunais do presente resultam em grande parte de estruturas precedentes, especialmente dos sindicatos inter-comunais. Esses últimos, inaugurados no século XIX, tem por característica uma atuação mais setorial e fragmentada para organização de serviços em rede, como é o caso da coleta de lixo, a proteção e gestão de recursos naturais e a gestão dos transportes públicos. Os sindicatos intercomunais assemelham-se, assim, aos nossos Consórcios Públicos.

Com efeito, na França as práticas cooperativas intercomunais são centenárias, e remontam ao traçado dos primeiros caminhos públicos, dos canais de abastecimento de água ou ao estabelecimento do sistema de saneamento. Eis a razão pela qual a cooperação inter-comunal não tardou a aparecer nos textos legislativos. Mas foram as novas leis definidas ao longo dos anos 1990 que forneceram o quadro legal necessário para ampliação e difusão das práticas cooperativas ${ }^{11}$. Nesse contexto, o papel do Estado francês foi fundamental para coordenação de interesses e promoção de um consenso em torno das vantagens da cooperação.

${ }^{11}$ A lei de 6 de fevereiro de 1992 sobre a Administração Territorial da República (ATR - ${ }^{\circ}$ 92-125) inaugurou duas modalidades diferentes de cooperação inter-comunal, assegurando às estruturas inter-comunais a possibilidade de arrecadar impostos: as "comunidades de aglomeração", para atingir as aglomerações urbanas; e as "comunidades de comunas", para abrigarem as comunas associadas em meio rural e de menor número de habitantes. No entanto, foi a lei ${ }^{\circ} 99-586$ de 12 de julho de 1999 , relativa ao fortalecimento e à simplificação da cooperação inter-comunal, que melhor esclareceu as competências e as prerrogativas de cada tipo de cooperação inter-comunal. Essa lei estabelece assim três tipos de estruturas de cooperação: as "comunidades urbanas", para as comunas associadas e que formam um conjunto de no mínimo 500.000 habitantes; as "comunidades de aglomeração", que agrupam entre 50.000 e 500.000 habitantes; e as "comunidades de comunas", que reúnem menos de 50.000 habitantes. 
NUNES, J. A contribuição teórica de Michel Mann em um estudo...

Leis claras e exaustivas estão assim na base do sucesso da cooperação inter-comunall na França.

No Brasil, a formação de Consórcios Intermunicipais é prevista na Constituição brasileira desde 1937, mas foi somente após a estabilização de um modelo de federalismo cooperativo que a lei 11.107 (2005) precisou as regras para a criação e os campos de atuação dos Consórcios Públicos Intermunicipais. O decreto que estabelece os detalhes desta nova legislação só foi promulgado em 2007. Assim, as experiências em matéria de cooperação intermunicipal são em maioria recentes, e os laços de reciprocidade entre os parceiros ainda não se estabilizaram. Em outros termos, o fator tempo parece ter um significado importante para sanar as incertezas e estreitar as relações entre os municípios.

No Brasil, a maior parte dos Consórcios resulta de políticas de incentivo realizadas pelas escalas superiores, sobretudo pelos Estados, que estimulam a criação de Consórcios Intermunicipais em suas próprias Constituições estaduais. Ademais, os Estados podem prestar apoio técnico, jurídico e financeiro para favorecer a cooperação entre municípios ${ }^{12}$. Dessa forma, diferentemente da França, onde as iniciativas partem dos atores locais (contando-se com uma forte e direta participação dos prefeitos), no Brasil, os Consórcios são afetados pelas mediações do pacto federativo, sendo muitas vezes criados de acordo com as vantagens ofertadas pelas escalas de gestão superiores. Estados e Governo federal são os principais financiadores dos Consórcios, dificilmente sustentados apenas com recursos municipais. Dito de outro modo, as trocas federativas e o tratamento verticalizado e setorial das políticas públicas estão na base do formato das práticas

${ }^{12}$ No Estado do Rio de Janeiro, os Consórcios são citados no Plano de Regionalização e no Plano de Investimentos do Estado para o período 2008-2011. Além disso, diversos seminários e workshops foram organizados pelo Estado do RJ nas suas regiões administrativas a fim de estimular a formação de Consórcios. Cf. Informações fornecidas pela Secretaria de Planejamento do Estado do Rio de Janeiro. Entrevistas realizadas em 8/10/2008. 
NUNES, J. A contribuição teórica de Michel Mann em um estudo...

cooperativas que se desenvolvem entre os municípios brasileiros. $\mathrm{Na}$ França, os departamentos ${ }^{13}$ são encarregados de organizar a cooperação inter-comunal em suas circunscrições, mas esse papel tem um caráter mais consultivo do que imperativo; permanece a cargo dos governos locais a decisão sobre os parceiros e os limites territoriais do espaço da cooperação.

Não menos importantes são, no Brasil, os problemas de sobreposição de competências, que dificultam ações coordenadas e enfraquecem o poder infra-estrutural do Estado (MANN, 1997). Considerando-se os entraves do município e os gargalos do pacto federativo, os problemas enfrentados pelos Consórcios refletem em muito os problemas dos próprios municípios na estrutura federativa brasileira.

Nos dois países, a importância da cooperação é porém evidente no quadro de insuficiência de recursos disponíveis nas escalas locais, sobretudo para a implantação e manutenção de equipamentos onerosos. Na França, o tamanho ínfimo de algumas comunas ${ }^{14}$ dificulta tanto a criação de certos equipamentos urbanos quanto o planejamento territorial. No Brasil, é também a insuficiência de recursos - técnicos, humanos, administrativos e financeiros - que incita à adoção de práticas cooperativas. Por essa razão, os Consórcios são tidos como estratégias sedutoras para os municípios menores ${ }^{15}$, notadamente para a prestação de serviços mais onerosos, como no caso dos serviços e equipamentos de saúde. Entretanto, os Consórcios parecem pouco sedutores quando se trata da prestação de serviços de proximidade, que exigem intervenções mais localizadas dos poderes públicos.

Outro ponto diz respeito à capacidade das comunas francesas para arrecadar recursos próprios. No Brasil, uma

\footnotetext{
13 Na França, os departamentos são recortes puramente administrativos que representam o Estado central nas escalas subnacionais.

14 As comunas menores abrigam menos de 50 habitantes e possuem menos de três hectares.

15 No contexto brasileiro, os municípios considerados como municípios pequenos possuem menos de 20.000 habitantes.
} 
NUNES, J. A contribuição teórica de Michel Mann em um estudo...

estrutura de cooperação intermunicipal é uma extensão dos poderes públicos municipais, não sendo autorizada a arrecadar impostos. Afinal, a arrecadação e o controle de recursos públicos devem ficar restritos a escalas de decisão cujos responsáveis passam pelo filtro da democracia representativa. Assim, os Consórcios são financiados ora por recursos transferidos pelos municípios participantes, ora por subvenções recebidas dos Estados. Na França, ainda que os delegados responsáveis pela gestão das estruturas de cooperação não sejam eleitos pelo voto direto ${ }^{16}$, as EPCIs podem arrecadar impostos, o que estreita os laços entre os parceiros e favorece as ações conjuntas. Além disso, a arrecadação própria amplia a autonomia financeira das comunas para a realização de investimentos nos espaços da cooperação. Essa inversão de papéis - o atrelamento dos Consórcios às políticas e recursos dos Estados e do Governo Federal, e a relativa autonomia política e econômica das estruturas inter-comunais francesas - nos remetem à própria complexidade do modelo federal brasileiro e à repartição de recursos e funções entre as escalas de poder. Seriam os municípios brasileiros mais dependentes do que imaginamos?

Ainda que esta apresentação seja breve, chama a atenção um elemento de contraste entre as duas sociedades. Na França, os serviços públicos fundamentais são bem distribuídos no território, e as políticas desenvolvidas pelas estruturas de cooperação intercomunais se concentram nos projetos de melhoria da qualidade de vida, de valorização e preservação do meio ambiente, além dos projetos de desenvolvimento econômico. No Brasil, a distribuição de bens e serviços públicos fundamentais, especialmente no campo da saúde e da educação, permanece na base das políticas de cooperação intermunicipal. Essa constatação ilustra as diferentes capacidades desses Estados para atingir a sociedade civil e ordenar

16 Os escrutínios para a eleição direta dos delegados inter-comunais passam a ocorrer a partir de 2014, conforme a reforma territorial aprovada pela Assembléia Nacional Francesa em 17 de novembro de 2010. 
NUNES, J. A contribuição teórica de Michel Mann em um estudo...

as rotinas em todo o território nacional.

Em suma, as maneiras de conceber a cooperação intermunicipal estão necessariamente relacionadas aos quadros institucionais nos quais essa prática se inscreve. À luz do federalismo cooperativo brasileiro, os municípios raramente se lançam em estruturas de cooperação intermunicipal sem o apoio técnico e financeiro dos Estados. Enquanto as comunas, inscritas no modelo unitário e descentralizado francês, parecem desfrutar de uma margem de manobra mais ampla. Tais sutilezas reforçam a importância do método comparativo para compreendermos nossa própria realidade. Nossa discussão ressalta ainda a relevância do diálogo interdisciplinar, ao valorizarmos as ferramentas teóricas desenvolvidas por Michael Mann sobre o poder infra-estrutural dos Estados e sua relação com a organização espacial da política. Porque o território é uma dimensão inescapável para o exercício do poder infra-estrutural dos Estados, as diferentes formas de organizá-lo afetam a capacidade do Estado para ordenar as rotinas e as práticas sociais. Enfim, consideramos que as práticas cooperativas intermunicipais abrem uma agenda de pesquisas que merece ser mais bem explorada no campo da Geografia Política, assim como os estudos comparativos sobre os resultados de políticas públicas similares em modelos de Estado distintos. 
NUNES, J. A contribuição teórica de Michel Mann em um estudo...

\section{Referências Bibliográficas}

BADIE, Bertrand; HERMET, Guy. La politique comparée. Paris : Armand Colin, 2001.

BORNAND, Elvire. «Raisonner par le territoire : les modalités pratiques de la coopération». In Faure, A., Négrier, E. (org.). Les politiques publiques à l'épreuve de l'action locale : critiques de la territorialisation. Paris: L'Harmattan, 2007. p. 147 - 152.

CALDAS, Eduardo de Lima. Formação de agendas governamentais locais : o caso dos Consorcios Intermunicipais. Tese de Doutorado (Doutorado em Ciência Política). Universidade de São Paulo, São Paulo, 2008.

CASTRO, Iná Elias de. "O território e o poder autônomo do Estado: uma discussão a partir da teoria de Michael Mann". Anais do VII Encontro Nacional da ANPEGE: Complexidade e desafios do pensar geográfico. Curitiba, 2009.

CASTRO, Iná Elias de. Geografia e Política: território, escalas de ação e instituições. Rio de Janeiro : Bertrand Brasil, 2005.

DUPRE, Michelle et. Al. «Les comparaisons internationales : intérêt et actualité d'une stratégie de recherche ». In Lallement, M., Spurk, J. (dir.). Stratégies de la comparaison internationale. Paris : CNRS Editions, 2003. p. 7-18,.

GAZIBO, Mamadou ; JENSON, Jaane. La politique comparée: fondaments enjeux et approches théoriques. Paris : Les Presses de l'Université de Montréal, 2004.

LEVY, Jaques. L'espace légitime : sur la dimension géographique de la fonction politique. Paris: Presses de la Fondation Nationale des Sciences Politiques, 1994.

MANN, Michael. "The autonomous power of the State' (1984) ». In Agnew, J. (ed.). Political Geography: a reader. London, New York, Sidney: Auckland, Arnold, p. 58-81, 1997.

MANN, Michael. The sources of social power: the rise of classes and nation-states, 1760-1914. Cambridge, New York: Cambridge University Press, 1988.

RETAILLE Denis. Le monde du géographe. Paris : Presses de Science Po, 1997.

RICHARD, Pierre ; COTTEN, Michel. Les communes françaises d'aujourd'hui. Paris : PUF, 1983.

NUNES, Juliana. La cooperation intercommunale : regards croisés entre la France et le Brésil. Université Jean Moulin Lyon 3 
NUNES, J. A contribuição teórica de Michel Mann em um estudo...

(Tese de Doutorado), 2010.

SCHROEDER, Ralph. "Introduction: the IEMP model and its critics". In Hall, J., Schoroeder, R.(ed.). An anatomy of power: the social theory of Michael Mann. Cambridge: Cambridge University Press, 2006. p. 1-16. WEISS, Linda. "Infrastructural power, economic transformation and globalization". In Hall, J.; Schroeder, R. (dir.). An anatomy of power: the social theory of Michael Mann. Cambridge: Cambridge University Press, 2006. p. 167-186.

Recebido em abril de 2011.

Aceito em maio de 2012. 